\title{
O trapeiro, a influenza e o esquecimento: \\ O Mez da Grippe e a teoria estética de Walter Benjamin
}

Rodrigo Vieira da Silva

UEPB

\begin{abstract}
Resumo: Em $O \mathrm{Mez}$ da Grippe, Valêncio Xavier parte do entrelaçamento entre recortes de jornais, fotografias, depoimentos de sobreviventes e anúncios publicitários do início do século passado, para produzir uma novela a partir das colagens desses fragmentos, numa narrativa que retrata uma Curitiba assolada pela gripe espanhola em 1918. O presente artigo se propõe a discutir os conceitos de estética narrativa segundo Walter Benjamin, a partir da análise da novela $O \mathrm{Mez}$ da Grippe, que busca, através de uma construção narrativa sofisticada que beira o experimentalismo, resgatar os rostos anônimos de uma Curitiba esquecida no tempo. $\mathrm{O}$ trabalho busca mostrar que a narrativa de Xavier condiz em vários aspectos com alguns pontos ressaltados pelo filósofo frankfurtiano Walter Benjamin em suas teorias estéticas e se destaca como uma literatura que luta para preservar fragmentos de memória que a sociedade quer apagar de sua lembrança.
\end{abstract}

Palavras-chave: Mez da Grippe. Estética. Esquecimento.

\section{Considerações em torno da Grippe valenciana}

Valêncio Xavier destaca-se como um dos maiores expoentes da literatura experimental brasileira, em sua obra $O$ Mez da Grippe (1981), constrói uma narrativa situada na Curitiba vitimada pela gripe espanhola no ano de 1918, narrando os pormenores de uma cidade assolada pela epidemia de influenza que ocorreu no Brasil em 1918. Tanto no que se diz respeito à temática quanto à linguagem utilizada pelo autor, $O \mathrm{Mez}$ da Grippe destaca-se por sua originalidade, pela inovação com a qual o autor conta sua história, com um texto extremamente plurissignificativo que envolve seus leitores, desafiando-os a decifrarem os vários significados de cada página da sua narrativa.

Xavier utilizou materiais inusitados como ferramentas para a construção de sua narrativa, como recortes de jornais da época em questão, anúncios publicitários, fotografias, depoimentos, letras de músicas e recortes ficcionais por ele criados, partindo de aspectos ora verídicos ora ficcionais para a construção de seu enredo, causando uma relação com o leitor que vai além do convencional, como afirma Pavloski: 
Desde as primeiras páginas de $O \mathrm{Mez}$ da grippe fica evidente que o tipo de relação que se estabelece entre texto e leitor se diferencia do tipo de comunicação ao qual estamos habituados a manter com outros universos textuais, possivelmente mais lineares, nos quais o grau de complementação da linguagem (ou linguagens) exigida para a configuração de sentido é sensivelmente menor. ${ }^{1}$

Ao mesclar o literário com o não-literário, a obra de Valêncio Xavier exemplifica muito bem o conceito defendido por Antonio Candido que a narrativa também "[...] se constitui a partir de materiais não literários, manipulados a fim de se tornarem aspectos de uma organização estética regida pelas suas próprias leis, não as da natureza, da sociedade ou do ser.",2

Portanto, pode-se perceber na obra de Valêncio Xavier o poder de uma literatura que se constrói a partir daquilo que, à primeira vista não é literário, mas que depois acaba se tornando, e possibilita que mantenhamos contato com territórios antes por nós desconhecidos, mundos que até então nunca havíamos explorado, como uma Curitiba devastada pela gripe espanhola que se torna conhecida por nós através dos recortes valencianos.

Um desses recônditos desconhecidos acaba sendo o próprio passado insondado, muitas vezes por nós inexplorado, deixando claro que uma das intenções de Valêncio Xavier é sondar esse passado muitas vezes relegado ao esquecimento, abandonado por aqueles que vivem o momento presente. Essa busca pelo passado por ele feita de modo quase obsessivo, monomaníaco, é uma constante em todas as suas obras, e pode ser justificada se nos remetermos às palavras de Octavio Paz, que afirmava que "a preservação da memória coletiva por um grupo, embora pequeno, é uma verdadeira tábua de salvação para a comunidade inteira."”

Como afirma Borba:

[...] falar da narrativa em Valêncio Xavier é se colocar perante um mundo pleno de possibilidades advindas das mais diversas formas de narrar. Suas narrativas [...] se fragmentam apresentando ao leitor imagens da cultura de massa existente numa outra época, por exemplo, como podemos observar em $\mathrm{O} \mathrm{Mez}$ da Grippe. ${ }^{4}$

A obra de Valêncio, buscando esse encontro com o passado, vai além de uma mera tentativa de narrar um fato ocorrido. Esse passado se reconstrói através da exploração de novas formas de se conceber a literatura, através de novos componentes que, muitas vezes, soam como estranhos, dissonantes, mas que encontram um fio narrativo que os une. Segundo Borba: 
É justamente esta narrativa que transborda, que vai além do simples ato de narrar, que se alinha, que se encontra com o pensamento de autores como Walter Benjamin [...] cuja obra vem nos apresentar uma modernidade constituída por um passado que se ativa a cada repetição, e que através da experiência do choque visa suscitar, reintegrar. ${ }^{5}$

Tendo em vista tais aspectos, deparamo-nos com um conjunto de indagações acerca da obra de Valêncio Xavier: O que seria esse objeto-alvo da reintegração valenciana? O que o autor espera encontrar ao esmiuçar esse passado? Quais verdades ele busca expor? De quais respostas ele necessita?

\section{1 - O Esquecimento benjaminiano}

Partindo da definição de Walter Benjamin de que a história não se constrói num tempo homogêneo e vazio, mas sim num tempo saturado pelo "agora", devemos entender alguns pontos básicos:

Em primeiro lugar, não podemos nos esquecer, seguindo a esteira de Benjamin, de seus apontamentos sobre a importância da narração para a constituição do sujeito e de sua contribuição à história em suas famosas Teses sobre o conceito de história, últimos escritos do filósofo, publicadas postumamente em 1940. Depois, devemos atentar que esse passado, só se deixa fixar a partir do momento em que é reconhecido, pois, para Benjamin, "articular historicamente o passado não significa conhecê-lo 'como ele de fato foi'. Significa apropriar-se de uma reminiscência, tal como ela relampeja num momento de perigo", 6 ou seja, para o autor, o passado não é descrito por nós, e sim articulado. É através do resgate do passado que se dá seu encontro com o presente, e por meio da conexão dessas duas épocas distintas que esse presente se reorganiza. Para Benjamin, devemos sempre impedir esse esquecimento, esse abandono total do passado, pois assim evitamos a barbárie ou a perda da memória. Sua visão da história parte de um princípio de contrariedade à história contínua, buscando a reescrita de uma história nunca acabada, o resgate da memória e a reconstrução de experiências significativas do passado.

A literatura acaba sendo um modo interessante de se fixar, de articular esse passado, de trazê-lo à tona uma vez mais, pois, segundo Gagnebin "hoje ainda, literatura e história enraízam-se no cuidado com o lembrar, seja para tentar reconstituir 
um passado que nos escapa, seja para 'resguardar alguma coisa da morte' (Gide) dentro da nossa frágil existência humana."7

É isso que Valêncio Xavier faz em $O$ Mez da Grippe: ele retrata uma Curitiba esquecida, repleta de anônimos relegados às névoas do passado e conta os detalhes do que aconteceu nessa cidade durante o surto de influenza em 1918. Como complemento à construção do cenário da época, deparamo-nos com ecos da Primeira Guerra Mundial que chegam até os habitantes por meio dos jornais daquele período. E assim, narrando o cotidiano dos sem-nome, a trama de $O \mathrm{Mez}$ da Grippe resgata os esquecidos, aqueles de quem não se ouviu falar e seus dilemas pessoais ante os inevitáveis desígnios da morte.

\section{2 - Os escombros que originam o novo}

Em seu ensaio Experiência e Pobreza (1933), Walter Benjamin defende que o aperfeiçoamento da técnica oriunda do capitalismo causa um empobrecimento e até mesmo a perda da experiência, marcando o fim das grandes narrativas, criadas seguindo um modelo convencional, tradicional, no qual havia uma transmissão de algo que pode ser desde uma experiência pessoal até um conhecimento mais generalizado.

Para o autor, a extinção da experiência tira dos homens o vínculo com a história, com a tradição, com o próprio passado. A narrativa, que antes era uma ponte entre o passado e o presente, entre o indivíduo e a tradição, o individual e o coletivo, não existe mais, restando apenas, no lugar do narrador que trazia em suas palavras toda uma carga de ensinamentos e experiências, um romancista solitário, que elabora uma literatura vazia, que não transmite experiência alguma para seu leitor, o qual, por sua vez, nada mais espera da literatura do que mero entretenimento escapista, refutando qualquer experiência que possa advir de suas leituras. Diagnosticando tal problema, Benjamin defende:

Pois qual o valor de todo o nosso patrimônio cultural, se a experiência não mais o vincula a nós? A horrível mixórdia de estilos e concepções do mundo do século passado mostrou-nos com tanta clareza aonde esses valores culturais podem nos conduzir, quando a experiência nos é subtraída, hipócrita ou sorrateiramente, que é hoje em dia uma prova de honradez confessar nossa pobreza. Sim, é preferível confessar que essa pobreza de experiência não é mais privada, mas de toda a humanidade. Surge assim, uma nova barbárie. ${ }^{8}$ 
E prossegue num tom melancólico:

Ficamos pobres. Abandonamos uma depois da outra todas as peças do patrimônio humano, tivemos que empenhá-las muitas vezes a um centésimo do seu valor para recebermos em troca a moeda miúda do "atual". 9

No entanto, nem tudo está perdido: com o total aniquilamento das narrativas tradicionais por meio do esquecimento, um novo tipo de narrativa surgirá, uma narrativa oriunda dos escombros, das ruínas da antiga narrativa e, junto com ela, surgirá uma nova concepção de narrador, mais humilde, sem tanta pompa ou triunfo, uma figura marginal que dará voz a uma narrativa segregada pela sociedade capitalista, uma literatura de malditos, marginais e esquecidos, que ainda assim carrega os componentes básicos da narrativa tradicional. Segundo Gagnebin:

O narrador também seria a figura do trapeiro, do Lumpensammler ou do chiffonier, do catador de sucata e de lixo, esta personagem das grandes cidades modernas que recolhem os cacos, os restos, os detritos, movido pela pobreza, certamente, mas também pelo desejo de não deixar nada se perder. ${ }^{10}$

Esse autor-trapeiro não visa registrar os grandes feitos; ele se concentra em apanhar, catalogar e colecionar aqueles fatos tidos como de menos importância para a história oficial - composta por aqueles eventos por ela escolhidos. O narradorsucateiro lida com os fatos com os quais a história oficial não sabe o que fazer e os abandona ao esquecimento. Para Benjamin, esses elementos excluídos do discurso histórico que são temas na obra de tais autores concentram-se em dois pontos principais: o sofrimento e o anonimato.

Na obra de Valêncio Xavier, percebemos de modo bastante claro esse tipo de preocupação por parte do autor: permeando toda a narrativa, vemos o sofrimento de uma cidade sendo exposto em todas as suas camadas, em alguns momentos de modo claro, em outros, de modo velado, sutil, mas, mesmo assim, presente. O anonimato torna-se presente no decorrer de toda a obra, na qual encontramos de modo recorrente figuras anônimas, personagens marginalizadas pela sociedade, loucos, pobres, presidiários, e a própria imagem da morte - talvez a maior das figuras rejeitadas pela humanidade, presente em todas as páginas de $\mathrm{OMez}$ da Grippe.

Outro ponto de cruzamento digno de destaque entre a obra de Valêncio Xavier e as teorias de Walter Benjamin é que Xavier trabalha com os estilhaços da história, com seus fragmentos abandonados, descontextualizando esses objetos e fazendo-os 
irradiar novos sentidos. Xavier é um autor que utiliza os fragmentos, os estilhaços, acumulando-os numa nova construção que desnuda o real. E já que o caráter histórico da linguagem está firmado sobre a noção de infinidade de significados, nada mais justo que o autor, como é o caso de Valêncio Xavier em $O$ Mez da Grippe, extraia de seus fragmentos de linguagem (recortes de jornais, fotografias, depoimentos etc.) o máximo de sentidos possíveis.

Além da nova concepção de narrador, Walter Benjamin refletiu também sobre uma mudança ocorrida na própria concepção da linguagem - por sinal, utilizada por Valêncio Xavier, levando-nos a pensar que talvez a forma convencional de narrativa não fosse capaz de dar conta da demanda informacional almejada pelo autor de $\mathrm{OMez}$ da Grippe - como ressaltado por Gagnebin:

Benjamin reúne reflexões [...] sobre a memória traumática, sobre a experiência do choque [...], portanto, sobre a impossibilidade, para a linguagem cotidiana e para a narração tradicional, de assimilar o choque, o trauma, diz Freud na mesma época, porque este, por definição, fere, separa, corta ao sujeito o acesso ao simbólico, em particular à linguagem. ${ }^{11}$

É exatamente esse retrato fiel do traumático alcançado através de uma nova forma de se contar uma história e essa mudança, essa renovação na linguagem um dos pontos mais característicos na narrativa de Valêncio Xavier.

A renovação na linguagem é uma das marcas mais presentes nos grandes autores da modernidade. Marshall Berman, em seu livro Tudo que é sólido desmancha no ar (1982), já apontava a renovação das formas de expressão vigentes como uma das principais características da arte moderna. Nomes como Baudelaire, Kafka, Joyce e Proust se destacaram por produzirem obras que renovavam a linguagem e as temáticas e acabaram por influenciar e ditar um caminho que seria seguido pela maioria dos autores do século XX.

Valêncio Xavier segue essa esteira de renovação da linguagem beirando o experimentalismo radical, inovando e corrompendo a definição maniqueísta entre o que é literário e o que não é. Em alguns momentos, Xavier chega a ecoar algo de Duchamp e suas definições sobre arte, como complementa Borba:

Neste sentido, pensar Valêncio Xavier a partir de Duchamp é ter em mente uma obra sendo construída a posteriori assim como o enigma, o hieróglifo, passa-se a ter uma formulação que nunca é a comunicação, e sim, um saber para poucos, ou melhor, para aqueles que saibam decifrar, ler cifras, ler entrelinhas. Duchamp foi quem 
nas artes plásticas teve a ousadia de questionar a arte e o próprio artista, e assim, construiu sua teoria se dedicando a questões relacionadas ao nominalismo e ao ready-made. Ou seja, Marcel Duchamp deu um xeque-mate na arte há quase um século, desde então ela (a Arte) ficou imóvel, prisioneira, dependente de uma solução que teria que passar pela desconstrução do impasse que criou. Duchamp cercou o conceito de Arte da época ao convencer seu público que tudo era arte, desde que alguém assim o quisesse, desde que o artista colocasse em qualquer objeto, modificado ou não, sua assinatura. ${ }^{12}$

Benjamin afirmava que um dos principais causadores do empobrecimento da experiência foi a difusão da imprensa no século XIX, no entanto, repetindo o conceito defendido por Antonio Candido, Xavier consegue tornar literário aquilo que não é, fazendo com que o texto jornalístico, esse grande vilão para Benjamin, se torne aliado do narrador, que poderá utilizá-lo e extrair dele uma gama infinita de significados.

Segundo Antonio Candido, em seu livro de ensaios Brigada Ligeira (2004):

O escritor é um indivíduo que exprime sempre uma ordem da realidade segundo um dado critério de interpretação. A técnica empregada é um instrumento de trabalho; um instrumento de trabalho que, embora visceralmente ligado ao conteúdo expressivo, pode ser usado para a expressão de mais de um conteúdo. ${ }^{13}$

Na primeira página de $O \mathrm{Mez}$ da Grippe temos um fragmento de jornal sobre a Primeira Guerra Mundial afirmando que "A paz está interrompida”, logo abaixo, temos um fragmento do Dr. Trajano Reis, diretor do serviço sanitário de Curitiba, detalhando como se iniciou a epidemia da gripe espanhola naquela cidade, a seguir temos o desenho de um homem e as seguintes palavras:

Um homem eu caminho sozinho

Nesta cidade sem gente

As gentes estão nas casas

A grippe. ${ }^{14}$

Nesse momento inicial da narrativa, percebemos a carga informacional que três fragmentos aparentemente aleatórios nos transmitem. Vistos de modo separado, parecem falar de coisas distintas, no entanto, quando se reúnem esses fragmentos, o mosaico que se formará irá retratar o cotidiano dessa Curitiba e seus dilemas ante a gripe espanhola e os tempos em que viviam.

$\mathrm{Na}$ página seguinte, temos outro recorte de jornal, novamente falando sobre a Grande Guerra, e logo abaixo, o anúncio de uma loja de cortinas. Desse modo, o autor 
vai construindo, através de pedaços esquecidos pelo tempo - seja de jornais, de propagandas, fotografias etc. - uma cidade inteira, cidade que ficou para trás, abandonada nas névoas de uma lembrança fugidia. E assim, Valêncio Xavier prossegue, dando voz aos esquecidos e retratando o cotidiano de uma cidade perdida no passado, vitimada por uma epidemia que varreu grande parte de sua população, resgatando, através de uma linguagem sofisticada-experimental, a memória dos mortos, dos doentes, e de todos aqueles que são abandonados nos porões do passado, nos remetendo às palavras de Benjamin em seu ensaio $O$ Narrador (1936):

O grande narrador tem suas raízes no povo, principalmente em suas camadas artesanais. [...] Comum a todos os grandes narradores é a facilidade com que se movem para cima e para baixo nos degraus de sua experiência, como numa escada. Uma escada que chega até o centro da terra e que se perde nas nuvens - é a imagem de uma experiência coletiva, para a qual mesmo o mais profundo choque da experiência individual, a morte, não representa nem um escândalo nem um impedimento. ${ }^{15}$

Valêncio Xavier se encaixa na figura desse homem do povo, uma figura que fala por muitos, que impede seu esquecimento nas malhas na história, movendo-se pelas várias camadas de uma Curitiba assolada pela Influenza, retratando vários eventos interligados com o contexto da epidemia num romance polifônico onde cada fragmento encerra um significado em si e que, quando anexado a outros fragmentos, constrói algo maior: o panorama fiel de uma cidade frente à experiência da morte.

\section{Considerações Gerais}

Assim, podemos perceber claramente que o modo como Valêncio Xavier constrói sua narrativa remete aos pontos elencados por Walter Benjamin ao definir o novo narrador surgido a partir do século XIX.

Além disso, é interessante notar que, em algumas passagens da obra de Xavier, mais importante do que as regras de composição literária são as regras de composição cinematográfica, como a edição e a montagem. A tesoura e a cola passam a deter uma importância tão grande quanto o próprio lápis. Outro ponto digno de destaque é a já apontada preocupação do autor paranaense em resguardar a memória dos mortos ao tratar a história a contrapelo abordando eventos esquecidos ou desconsiderados pela História oficial, que chega a reforçar ainda mais seu papel de narrador benjaminiano, afinal, uma das grandes características da pós-modernidade é o total obnubilamento do 
passado histórico, sobretudo naquilo que se refere à história dos derrotados e, no caso de Xavier, dos mortos pela gripe espanhola em uma cidade brasileira no início do século passado.

Por fim, pode-se afirmar que Valêncio Xavier produz literatura a partir dos dejetos da sociedade, do lixo, como o próprio já afirmou em várias entrevistas a revistas e jornais. Desse modo, descontextualizando objetos de seus pontos de origem, como recortes de jornais, documentos oficiais, anúncios e fotografias, esse autorsucateiro faz com eles passem a irradiar novos sentidos, provando que acima de tudo, a matéria-prima de sua literatura é aquilo que, à primeira vista, não soa como literário, mas que pode vir a ser.

Abstract: In $\mathrm{O} \mathrm{Mez} \mathrm{da} \mathrm{Grippe,} \mathrm{Valêncio} \mathrm{Xavier} \mathrm{uses} \mathrm{the} \mathrm{interweavement} \mathrm{of} \mathrm{newspaper}$ clippings, photographs, survivors' testimonials and commercial advertisement from the beginning of last century to create a novel, so as to make collages of those fragments into a narrative that depicts Curitiba desolate by the Spanish Flu in 1918. This article aims to discuss the concepts of narrative aesthetics, according to Walter Benjamin, by analyzing the novel $O$ Mez da Grippe, which seeks, through a sophisticated narrative whose construction borders on experimentalism, to rescue the anonymous faces of a Curitiba forgotten in time. This piece of work attempts to argue that Xavier's narrative is connected in many ways with some points highlighted by the Frankfurt School philosopher Walter Benjamin in his aesthetic theories and stands out as a literature that strives to preserve fragments of memory that society wants to erase from its memory.

Keywords: Mez da Grippe. Aesthetics. Oblivion.

\section{Referências Bibliográficas}

BENJAMIN, Walter. Obras escolhidas. Vol. I: Magia e técnica, arte e política. São Paulo: Brasiliense, 1994.

BERMAN, Marshall. Tudo que é sólido desmancha no ar. São Paulo: Companhia das Letras, 2007.

BORBA, Maria Salete. Para além da escritura: O "não puro" existente na obra de Valêncio Xavier. s/d. Disponível em http://www.ceart.udesc.br/PosGraduacao/revistas/2003/2003/salete/salete.htm. Acesso em 07/01/2010.

CANDIDO, Antonio. O discurso e a cidade. Ouro sobre azul: São Paulo, Rio de Janeiro, 2004.

CANDIDO, Antonio. Brigada Ligeira. Ouro sobre azul: São Paulo, Rio de Janeiro, 2004.

GAGNEBIN, Jeanne Marie. História e narração em Walter Benjamin. São Paulo: Perspectiva, 2004.

GAGNEBIN, Jeanne Marie. Lembrar escrever esquecer. São Paulo: Editora 34, 2006. 
PAVLOSKI, Evanir. Linguagem, história, ficção e outros labirintos em 'O mez da grippe' de Valêncio Xavier. Revista Letras, Curitiba, N. 66, P. 45-60, Maio/Ago. 2005. Editora UFPR.

PAZ, Octavio. A outra voz. São Paulo: Siciliano, 1993.

XAVIER, Valêncio. O Mez da Grippe e Outros Livros. São Paulo: Companhia das Letras, 1998.

\section{Notas}

${ }^{1}$ PAVLOSKI. Linguagem, história, ficção e outros labirintos em 'O mez da grippe' de Valêncio Xavier, p. 45.

${ }^{2}$ CANDIDO. O discurso e a cidade, p. 9

${ }^{3}$ PAZ. A outra voz, p. 80.

${ }^{4}$ BORBA. Para além da escritura: O "não puro" existente na obra de Valêncio Xavier, p. 01.

${ }^{5}$ BORBA. Para além da escritura: O "não puro" existente na obra de Valêncio Xavier, p. 01.

${ }^{6}$ BENJAMIN, Walter. Obras escolhidas. Vol. I: Magia e técnica, arte e política, p. 224.

${ }^{7}$ GAGNEBIN. História e narração em Walter Benjamin, p. 03.

${ }^{8}$ BENJAMIN, Walter. Obras escolhidas. Vol. I: Magia e técnica, arte e política, p. 115.

${ }^{9}$ BENJAMIN, Walter. Obras escolhidas. Vol. I: Magia e técnica, arte e política, p. 119.

${ }^{10}$ GAGNEBIN. Lembrar escrever esquecer, p. 53.

${ }^{11}$ GAGNEBIN. Lembrar escrever esquecer, p. 51.

${ }^{12}$ BORBA. Para além da escritura: O "não puro" existente na obra de Valêncio Xavier, p. 02.

${ }^{13}$ CANDIDO. Brigada Ligeira, p. 64-65.

${ }^{14}$ XAVIER. O Mez da Grippe e Outros Livros, p. 13.

${ }^{15}$ BENJAMIN, Walter. Obras escolhidas. Vol. I: Magia e técnica, arte e política, p. 214-215. 